\title{
Effects of supplementation with a phytobiotics-rich herbal mixture on performance, udder health, and metabolic status of Holstein cows with various levels of milk somatic cell counts
}

\author{
F. Hashemzadeh-Cigari, ${ }^{\star 1}$ M. Khorvash, ${ }^{*}$ G. R. Ghorbani, ${ }^{*}$ M. Kadivar,† A. Riasi, ${ }^{*}$ and Q. Zebelił \\ *Department of Animal Science, Isfahan University of Technology, Isfahan 84156, Iran \\ †Department of Food Science and Technology, College of Agriculture, Isfahan University of Technology, Isfahan, 84156-83111, Iran \\ łInstitute of Animal Nutrition and Functional Plant Compounds, Vetmeduni, 1210 Vienna, Austria
}

\begin{abstract}
This study evaluated the effects of dietary supplementation of a novel phytobiotics-rich herbal mixture (PRHM) on feed intake, performance, udder health, ruminal fermentation, and plasma metabolites in cows with moderate or high somatic cell counts (SCC) in the milk. Twenty-four Holstein dairy cows $(117 \pm 26$ $\mathrm{d}$ in milk and $46.3 \pm 4.7 \mathrm{~kg}$ of milk/d at the start of the experiment) were blocked by parity and days in milk and split into 2 groups, based on SCC in the milk; 12 cows were with moderate SCC $(260,000<$ SCC $<500,000$ cells $/ \mathrm{mL}$ ), whereas 12 other cows had high levels of SCC $(>500,000$ cells $/ \mathrm{mL})$ in the milk. Within each SCC group, cows were blocked by milk yield and parity, and were randomly assigned to 2 different feeding regimens. Half of the cows in each SCC group (n $=6$ ) were supplemented with PRHM (185 g/cow per day, providing $12.4 \mathrm{~g}$ of phenolic compounds per day), and the other half $(\mathrm{n}=6)$ were not supplemented in their diets. The experiment lasted $36 \mathrm{~d}$, whereby the first $24 \mathrm{~d}$ were used for adaptation to the diets and the last $12 \mathrm{~d}$ for sampling. Data showed that supplementation of PRHM decreased somatic cell score in the milk, indicating improved udder health of cows with high initial SCC, but not in cows with moderate SCC. Also, cows supplemented with PRHM consumed more feed DM, produced greater amounts of milk, and showed an improvement of feed utilization efficiency. However, these cows also lost more back-fat thickness during the experiment. Supplementation of PRHM increased fat- and energy-corrected milk yields in cows with high initial SCC, but not in cows with moderate SCC. Supplementation of PRHM decreased milk fat content, whereas other milk components were not affected by PRHM feeding. The PRHM supplementation decreased the acetate-to-propionate ratio in the rumen fluid, but
\end{abstract}

Received January 28, 2014.

Accepted June 23, 2014.

${ }^{1}$ Corresponding author: hashemzadeh.farzad@gmail.com increased $\beta$-hydroxybutyrate and cholesterol concentration in the plasma, irrespective of the initial SCC level in the milk. Other plasma metabolites and liver enzymes were not affected by PRHM supplementation. Apparent nutrient digestibility did not differ among treatments. Overall, supplementation of PRHM seems to be an effective strategy to enhance performance and lower SCC, particularly in cows having high SCC levels in the milk. Further research is warranted to evaluate long-term effects of PRHM supplementation, especially with regard to metabolic health status and reproduction.

Key words: phytobiotics supplementation, mammary health, milk production, dairy cow

\section{INTRODUCTION}

Elevated SCC in milk indicate poor udder health status and milk quality, representing a major concern of modern dairy herds (Schukken et al., 2003). Cows with elevated SCC produce less milk than their healthy counterparts, leading to significant economic losses to the dairy industry. Indeed, approximately $70 \%$ of the costs related to subclinical mastitis are associated with temporary or permanent decreases in milk production, mainly due to inflammatory damage of the mammary tissue (Zhao and Lacasse, 2008).

In general, nutritional factors have been discussed to play a key role in enhancing resistance against mammary infections (Politis, 2012), and supplementation of diets with excessive amounts of micronutrients with potent antioxidant and immune-enhancing properties, such as vitamin $\mathrm{E}, \mathrm{Se}, \mathrm{Zn}$, and $\mathrm{Cu}$, are reported to enhance udder health (Scaletti et al., 2003; Politis, 2012). Yet, in contrast to early published literature, newly published data unexpectedly has shown that an overload of vitamin E may adversely affect udder health and increase mastitis incidence (Bouwstra et al., 2010). It is also known that the status of vitamin $\mathrm{C}$ is compromised during mammary infections (Weiss et al., 2004), suggesting a depletion of water-soluble antioxi- 
dants during mammary infections, with consequences of lower vitamin E efficiency and health status. These data also highlight the importance of seeking alternative antioxidants, especially from hydrophilic sources, for improving the antioxidant status of the body, and possibly increasing the efficiency of vitamin E, to improve udder health (Gobert et al., 2009; Bouwstra et al., 2010).

Phytobiotics, commonly known as herbal plant bioactive compounds, have been used in human and veterinary medicine to prevent diseases, enhance performance in stress-related syndromes, and increase resistance against infections (Rochfort et al., 2008). Phytobiotics are largely used in ruminant nutrition due to their antimicrobial activity to mitigate methane emissions and improve ruminal fermentation efficiency (Khiaosa-ard and Zebeli, 2013). Besides their antimicrobial activity, a large body of evidence has shown that phytobiotics have strong antioxidant and antiinflammatory activities. Previously, it has been reported that clove, rosemary, cinnamon, and turmeric, which were used in the present study, were at the top of the list regarding their antioxidant potential in vitro (Dragland et al., 2003). These compounds also were previously tested for their strong in vivo antioxidant and antiinflammatory activity. For example, Roussel et al. (2009) reported that inclusion of aqueous extract of cinnamon in the diet could improve antioxidant status of obese people with impaired fasting glucose. It has also been demonstrated that rosemary and turmeric extract as well as clove bud could inhibit the lipid peroxidation and alleviate oxidative stress of healthy mice or diabetic rats (Asai et al., 1999; Bakirel et al., 2008; Shukri et al., 2010). Additionally, it has been demonstrated that synergism between phytobiotics in herbal plants are mainly responsible for their potent health-enhancing properties. Therefore, combinations of antioxidants with possible synergism are preferred for preventing free-radicalinduced disorders (Liu, 2004). Our preliminary experiment showed that quaternary mixtures of herbs, which are used in the present study, exhibited synergistic antioxidant activity (20 to $29 \%$ ) relative to the activity of each single herb (unpublished data). This suggests that the combining of herbs potentiates positive response of each single herb, leading to an increased antioxidant activity due to a potential additive effect.

Gladine et al. (2007) demonstrated that extracts of 4 herbs, including rosemary, marigold, citrus, and grape, kept their antioxidant capacity in vivo in sheep as a ruminant model. In an ongoing later study, Gobert et al. (2009) demonstrated that combinations of the mentioned herbal extracts, when supplied in association with vitamin $\mathrm{E}$, were able to reduce oxidative stress in lactating cows given a diet rich in n-3 FA. Those researchers stated that the combination of herbal extracts as a hydrophilic antioxidant may synergistically interact with lipophilic antioxidants such as vitamin E and result in an enhanced antioxidant status. New evidence suggests that phytobiotic supplementation may be more efficient in animals that are under physiologic or environmental stress conditions (Gobert et al., 2009). With regard to the earlier mentioned beneficial effects of phytobiotics, we hypothesized that supplementation of phytobiotics-rich herbal mixtures (PRHM) to high-producing dairy cows that are prone to subclinical udder health disorders may alleviate this stressful condition and, consequently, improve their lactation performance and health status. The objective of this study was to determine the effects of supplementation of a novel PRHM on feed intake, lactation performance, udder health status, ruminal fermentation, and blood metabolites in dairy cows with moderate or high SCC in the milk.

\section{MATERIALS AND METHODS}

\section{Cows, Diets, and Experimental Design}

The study was conducted at the facilities of a dairy farm (FKA Animal Husbandry and Agriculture Co., Isfahan, Iran), and was previously approved by the Animal Care and Use Committee of the Iranian Council of Animal Care (1995). Twenty-four multiparous lactating Holstein cows, averaging $117 \pm 26$ DIM and $46.3 \pm 4.7$ $\mathrm{kg}$ of milk/d at the start of experiment, were blocked by DIM and parity, and split into 2 groups, based on the preexperimental SCC in their milk: 12 cows with moderate SCC $(260,000<$ SCC $<500,000$ cells $/ \mathrm{mL}$; mean \pm SD: $325,833 \pm 36,168$ cells $/ \mathrm{mL}$ ) and 12 cows with high SCC $(>500,000$ cells $/ \mathrm{mL}$; mean $\pm \mathrm{SD}: 775,750 \pm 239,813$ cells $/ \mathrm{mL}$ ). Cows in the moderate-SCC group were 115 \pm 21 DIM and of parity $4.08 \pm 0.90$, whereas cows in the high-SCC group were $118 \pm 17$ DIM and of parity $4.00 \pm 0.79$. Within each group, cows were blocked by milk yield and randomly allocated to 2 different feeding regimens, resulting in a $2 \times 2$ factorial arrangement of treatments: (1) moderate-SCC level supplemented with PRHM, (2) moderate-SCC level unsupplemented with PRHM, (3) high-SCC level supplemented with PRHM, and (4) high-SCC level unsupplemented with PRHM. The experiment lasted $36 \mathrm{~d}$, with the first $24 \mathrm{~d}$ used as adaptation to diets and the last $12 \mathrm{~d}$ as sampling period. Throughout the experiment, cows were housed in individual $8 \times 4 \mathrm{~m}$ stalls, had free access to water, and were fed a TMR twice daily at 1000 and $1600 \mathrm{~h}$ for ad libitum intake to allow for 5 to $10 \%$ refusals. Ingredients and chemical composition of the experimental diet are given in Table 1. 
Table 1. Dietary ingredients and nutrient composition (DM basis) of experimental diet

\begin{tabular}{lc}
\hline Item & Amount \\
\hline Ingredient (\% of DM) & \\
Corn silage & 23.39 \\
Alfalfa hay & 8.67 \\
Whole cottonseeds & 3.77 \\
Beet pulp & 3.77 \\
Ground barley & 21.24 \\
Ground corn & 13.67 \\
Extruded soybean & 2.41 \\
Fish meal & 1.90 \\
Soybean meal & 12.47 \\
Fat powder & 2.03 \\
Cottonseed meal & 3.47 \\
Sodium bentonite & 0.27 \\
Magnesium oxide & 0.27 \\
Biotin & 0.006 \\
Sodium bicarbonate & 1.024 \\
Dicalcium phosphate & 0.27 \\
Calcium carbonate & 0.67 \\
Salt & 0.34 \\
Mineral and vitamin premix ${ }^{1}$ & 0.36 \\
Chemical composition (\% of DM, unless otherwise noted) & \\
NE (Mcal/kg) & 1.72 \\
DM (\%) & 52.4 \\
OM & 91.8 \\
CP & 16.6 \\
NDF & 32.4 \\
ADF & 18.2 \\
NFC & 41.3 \\
\hline Compsion $5 \%$ of Ca/kg & \\
\hline
\end{tabular}

${ }^{1}$ Composition: $50 \mathrm{~g}$ of $\mathrm{Ca} / \mathrm{kg}, 11 \mathrm{~g}$ of $\mathrm{Mg} / \mathrm{kg}, 5 \mathrm{~g}$ of $\mathrm{Mn} / \mathrm{kg}, 15 \mathrm{~g}$ of $\mathrm{Zn} / \mathrm{kg}, 3 \mathrm{~g}$ of $\mathrm{Cu} / \mathrm{kg}, 0.15 \mathrm{~g}$ of I/ $\mathrm{kg}, 0.05 \mathrm{~g}$ of $\mathrm{Co} / \mathrm{kg}, 1,800,000 \mathrm{IU}$ of vitamin $\mathrm{A} / \mathrm{kg}, 200,000 \mathrm{IU}$ of vitamin $\mathrm{D} / \mathrm{kg}$, and 15,000 IU of vitamin $\mathrm{E} / \mathrm{kg}$, and $1.25 \mathrm{~g}$ of butylated hydroxytoluene $/ \mathrm{kg}$ as a synthetic antioxidant. Minerals and vitamins were separately packaged and used in equal proportion.

Dried cinnamon bark (Cinnamomum zeylanicum), turmeric roots (Curcuma longa), rosemary leaves (Rosmarinus officinalis), and clove buds (Eugenia caryophyllata Thunb.) were purchased in a single lot from a local market in Isfahan, Iran, and stored in cool and dry place. Herbal mixtures were ground through a 1-mm screen using a Wiley mill (Arthur H. Thomas Co., Philadelphia, PA) and mixed in the proportion of $60 \%$ rosemary, $18 \%$ cinnamon bark, $18 \%$ turmeric, and $4 \%$ clove bud, weekly. The PRHM was supplemented at a rate of $185 \mathrm{~g} /$ cow per day throughout the experiment and the mixture contained, on average, $67.2 \mathrm{~g}$ of phenolic compounds per kilogram of PRHM. To minimize palatability problems, the PRHM were mixed with a portion of shredded sugar beet pulp and top-dressed, and attention was paid that most of the PRHM was ingested.

\section{Sampling and Chemical Analysis}

Amounts of feed offered and refused were recorded daily from d 24 to 36 to determine the feed intake of cows by difference. Fecal grab samples were collected at $1400 \mathrm{~h}$ for 4 consecutive days from d 30 to 34 of the experiment. All samples were frozen at $-18^{\circ} \mathrm{C}$ for subsequent chemical analysis. Dry matter content of feed, orts, and fecal samples was determined after oven drying for $72 \mathrm{~h}$ at $55^{\circ} \mathrm{C}$ and grinding through a 1-mm screen using a Wiley mill (Arthur H. Thomas Co.). The ground samples were analyzed for Kjeldahl N (AOAC, 1990; method 988.05), ether extract (AOAC, 1990; method 920.39), and ash (AOAC, 1990; method 942.05) content. The NDF and ADF contents were determined using the methods described by Van Soest et al. (1991), with heat-stable $\alpha$-amylase used in the NDF procedure (Van Soest et al., 1991). Acid-insoluble ash content of feed and feces was used as an internal marker for calculating apparent total-tract digestibility of DM and OM, as described by Van Keulen and Young (1977).

For evaluating the in vitro antioxidant properties of the herbal plants used, herbal materials were powdered in a laboratory grinder (Arthur H. Thomas Co.). Plant extract preparation and measurement of total phenolic compounds with Folin-Ciocalteu phenol reagent were conducted using the methods described by Bamdad et al. (2006). The antioxidant activity was measured on the basis of the stable 1,1-diphenyl 2-picrylhyorazyl free radical scavenging activity (DPPH-RSA) according to the method previously described by Bamdad et al. (2006). This was expressed as inhibition percentage and calculated using the formula DPPH-RSA $(\%)=$ (control OD - sample OD/control OD) $\times 100$, where $\mathrm{OD}=$ optical density (absorbance) at $517 \mathrm{~nm}$. Total phenolic contents and DPPH-RSA of each herbal plant and vitamin E $(50 \mathrm{mg} / \mathrm{L}$; Sigma-Aldrich, St. Louis, MO) are shown in Table 2.

Body condition score was recorded at the beginning and end of the experiment, using a scale from 1 to 5 with 0.25 -point increments, where $1=$ thin and $5=$ extremely fat by the same trained observer (Ferguson et al., 1994). Additionally, back-fat thickness (BFT) was measured at the beginning and end of the experiment using a portable B-mode ultrasound generator (SonoVet 600V; BCF Technology Ltd., West Lothian,

Table 2. Total phenolic content (TPC) and the 1,1-diphenyl 2-picrylhyorazyl radical scavenging activity (DPPH-RSA) of herbal extracts as a measure of their antioxidant activity

\begin{tabular}{lcc}
\hline & $\begin{array}{c}\text { TPC } \\
\text { Plant extract }\end{array}$ & $\begin{array}{c}\text { DPPH-RSA } \\
(\%)\end{array}$ \\
\hline Cinnamon bark & 58.5 & 70.8 \\
Turmeric root & 31.3 & 26.5 \\
Rosemary leaves & 77.7 & 82.4 \\
Clove bud & 110.2 & 90.1 \\
Vitamin E, 50 mg/L & - & 91.8 \\
SEM & 0.77 & 1.1 \\
\hline
\end{tabular}

${ }^{1} \mathrm{TAE}=$ tannic acid equivalents. 
UK) with a linear transducer and a frequency between 5.0 and 6.5 MHz (Schröder and Staufenbiel, 2006).

\section{SCC and Milk Production}

To determine the SCC level for including cows in the study, milk samples were collected at $16,15,3$, and $2 \mathrm{~d}$ before the onset of the experiment from 3 consecutive milkings $(0500,1300$, and $2100 \mathrm{~h})$ and preserved using sodium dichromate. Following washing and drying of the mammary teats, each teat end was scrubbed with a disposable towel saturated in ethyl alcohol (70\%). The first streams of foremilk were discharged. Visual examination of milk samples was done to detect signs of mastitis or other lesions. Before starting the milking, the milking machine was washed according to standard protocols, and then the cows were milked. After each milking, the milk yields of individual cows were recorded and milk samples were collected in sterile tubes and maintained in chilled condition during their transport to laboratory. Cows in the defined SCC ranges $(260,000-500,000$ or $>500,000$ cells $/ \mathrm{mL})$ were enrolled in the experiment. Despite a few cases where small clots were observed in the milk, cows did not show any clinical signs of acute mastitis requiring medical treatment. Therefore, none of the cows received medical treatment throughout the present experiment. Cows with high SCC levels were considered as having subclinical mastitis.

To collect data on milk yield and composition, experimental cows were milked 3 times daily at 0500, 1300 , and $2100 \mathrm{~h}$ in the milking parlor and milk yields were recorded daily during the sampling period. Milk samples were collected on d 26 to 32 of the experiment from 3 consecutive milkings and preserved using sodium dichromate. Milk samples were analyzed for fat, protein, lactose, TS, SNF, and SCC using a MilkoScan analyzer (Foss Electric A/S, Hillerød, Denmark).

\section{Ruminal Fermentation and Blood Metabolites}

Rumen fluid sampling and analyses of VFA were done according to Kargar et al. (2012). Briefly, at the end of sampling period, rumen fluid (10 to $20 \mathrm{~mL}$ ) from the ventral sac was sampled using the rumenocentesis technique. Rumen samples were obtained at $4 \mathrm{~h}$ after the morning feeding. The $\mathrm{pH}$ of the ruminal fluid was immediately determined using a portable digital $\mathrm{pH}$ meter (HI 8318; Hanna Instruments, Cluj-Napoca, Romania) and samples were immediately frozen at $-18^{\circ} \mathrm{C}$. Upon thawing at room temperature (i.e., $20^{\circ} \mathrm{C}$ ), ruminal fluid was prepared for VFA analysis by gas chromatography (Chrompack, model CP-9002; Chrompack Interna- tional BV, Middelburg, the Netherlands) using a 50-m (0.32-mm i.d.) fused silica column (CP-Wax Chrompack Capillary Column; Varian Inc., Palo Alto, CA), and crotonic acid was used as the internal standard. Nitrogen was used as carrier gas and oven initial and final temperatures were 55 and $195^{\circ} \mathrm{C}$, respectively, and detector and injector temperatures were set at $250^{\circ} \mathrm{C}$. Ammonia $\mathrm{N}$ concentration was determined by the colorimetric phenol-hypochlorite method of Broderick and Kang (1980).

Blood samples were collected approximately $4 \mathrm{~h}$ after the morning feeding from the coccygeal vein using heparinized Vacutainer tubes (Becton Dickinson, Rutherford, NJ).on d 35 of the experiment. All tubes were centrifuged at $1,850 \times g$ for $20 \mathrm{~min}$ at $4^{\circ} \mathrm{C}$. The plasma samples were obtained and frozen $\left(-20^{\circ} \mathrm{C}\right)$ until analysis. The concentration of plasma glucose [glucose oxidase-phenol 4-aminoantipyrine peroxidase (GODPAP) method], cholesterol [cholesterol oxidase-phenol 4-aminoantipyrine peroxidase (CHOD-PAP) method], BUN (Berthelot method), triglyceride [glycerol-3-phosphate oxidase-phenol 4-aminoantipyrine peroxidase (GPO-PAP) method], total protein (Biuret method), albumin (bromocresol green method), creatinine (Jaffe method), alanine aminotransferase [International Federation of Clinical Chemistry (IFCC) method], and aspartate aminotransferase (IFCC method), alkaline phosphatase [DGKC (German Society for Clinical Chemistry) method] were measured using commercial kits (Pars Azmoon Co., Tehran, Iran) according to the manufacturer's instructions. Globulin concentrations were obtained by deducting albumin from total protein. Concentrations of BHBA of plasma samples were determined with commercial colorimetric kits (Randox Laboratories Ltd., Ardmore, UK). Globulin concentrations were obtained by deducting albumin from total protein.

\section{Statistical Analysis}

Data were analyzed according to a split-plot design using PROC MIXED of SAS (SAS Institute Inc., Cary, NC). The main plot consisted of the levels of SCC (moderate vs. high), and the subplot factor involved the supplementation with PRHM or not. The model included the fixed effects of treatment (SCC levels, PRHM, and their 2-way interactions), the random effect of cows nested within block, and the residual error. Pretreatment data for DMI, milk production, milk components, BCS, and BFT were used as the covariate adjustment. Data from the same animal but taken on different days were considered as repeated measures, and appropriate variance-covariance matrixes were 
modeled to account for them. A threshold of significance was set at $P \leq 0.05$; trends were declared at 0.05 $<P<0.10$.

\section{RESULTS}

\section{DMI and Performance}

Data showed that PRHM supplementation to cows with moderate milk SCC, but not high SCC, resulted in higher DMI than unsupplemented cows $(P<0.05)$. Digestibility of DM and OM were not affected by the PRHM supplementation or the SCC level $(P>0.10$; Table 3).

Milk production was greater in cows supplemented with PRHM $(P=0.05)$. Cows with high SCC tended to produce less milk compared with moderate SCC. Supplementing PRHM decreased milk fat content $(P<$ 0.01 ), whereas other milk components were not affected by PRHM addition. Feed efficiency was improved in cows supplemented with PRHM (1.66 vs. 1.54; $P<$ $0.10)$; however, the latter cows had lower BFT at the end of experiment and they lost more BFT during the experimental period $(P<0.05)$. Cows with moderate SCC in milk tended to have higher feed efficiency than cows with high SCC in milk (1.67 vs $1.54 ; P=0.06$ ). As shown in Figure 1, an interaction existed between milk SCC and PRHM supplementation for milk SCS, as cows with initial high SCC supplemented with PRHM had lower SCS than unsupplemented initially high-SCC cows (5.49 vs. $5.89 \log _{10}$ cells $/ \mathrm{mL} ; P<0.05$ ), whereas this response was not observed in cows with moderate SCC (5.26 vs. $5.15 \log _{10}$ cells $\left./ \mathrm{mL} ; P>0.10\right)$. Interactions between initial SCC level and PRHM supplementation were significant $(P<0.05)$ regarding FCM, fat- and protein-corrected milk, and ECM, whereby the PRHM addition was effective in increasing the latter variables in initially high-SCC cows, but not in cows with moderate SCC. No interaction was detected between the SCC level and PRHM supplementation for milk composition variables $(P>0.10)$.

\section{Ruminal Fermentation}

Ruminal pH, ammonia-N, total VFA concentration, and molar proportion of propionate and butyrate were not affected by the PRHM supplementation or the SCC level $(P>0.10)$, whereas PRHM supplementation lowered the acetate-to-propionate ratio $(P=0.05)$, and tended to lower the acetate molar percentage $(P$

Table 3. Performance of dairy cows at two levels of SCC in the milk after supplementation with a novel phytobiotics-rich herbal mixture (PRHM) or not (NO)

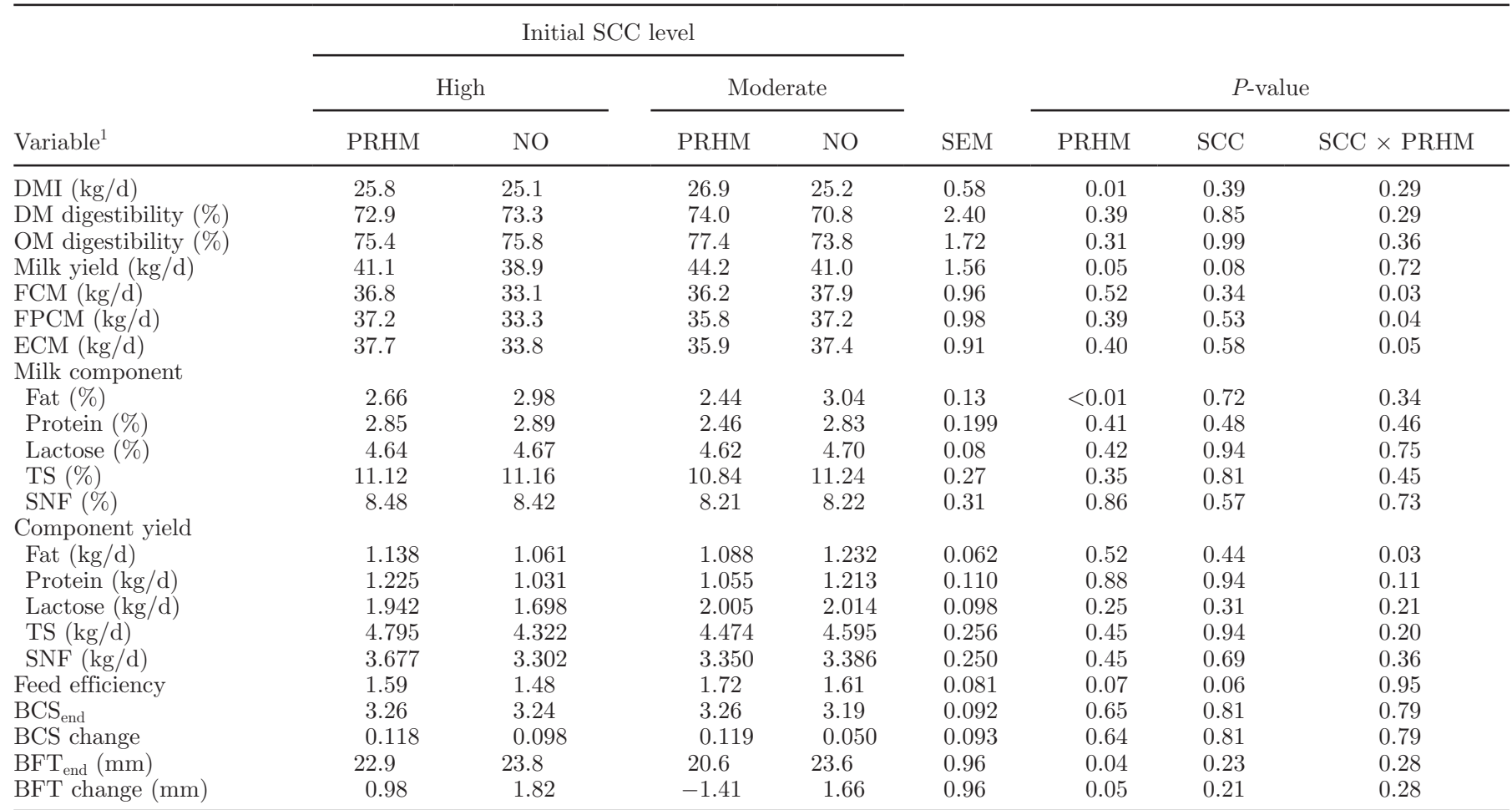

${ }^{1} \mathrm{FPCM}=$ fat- and protein-corrected milk; feed efficiency = kilograms of milk per kilogram of DMI; $\mathrm{BCS}_{\text {end }}=\mathrm{BCS}_{\text {at }}$ the end of the experiment; $\mathrm{BFT}_{\text {end }}=$ back-fat thickness at the end of the experiment; BCS and BFT change = changes from the start to the end of the experiment. 


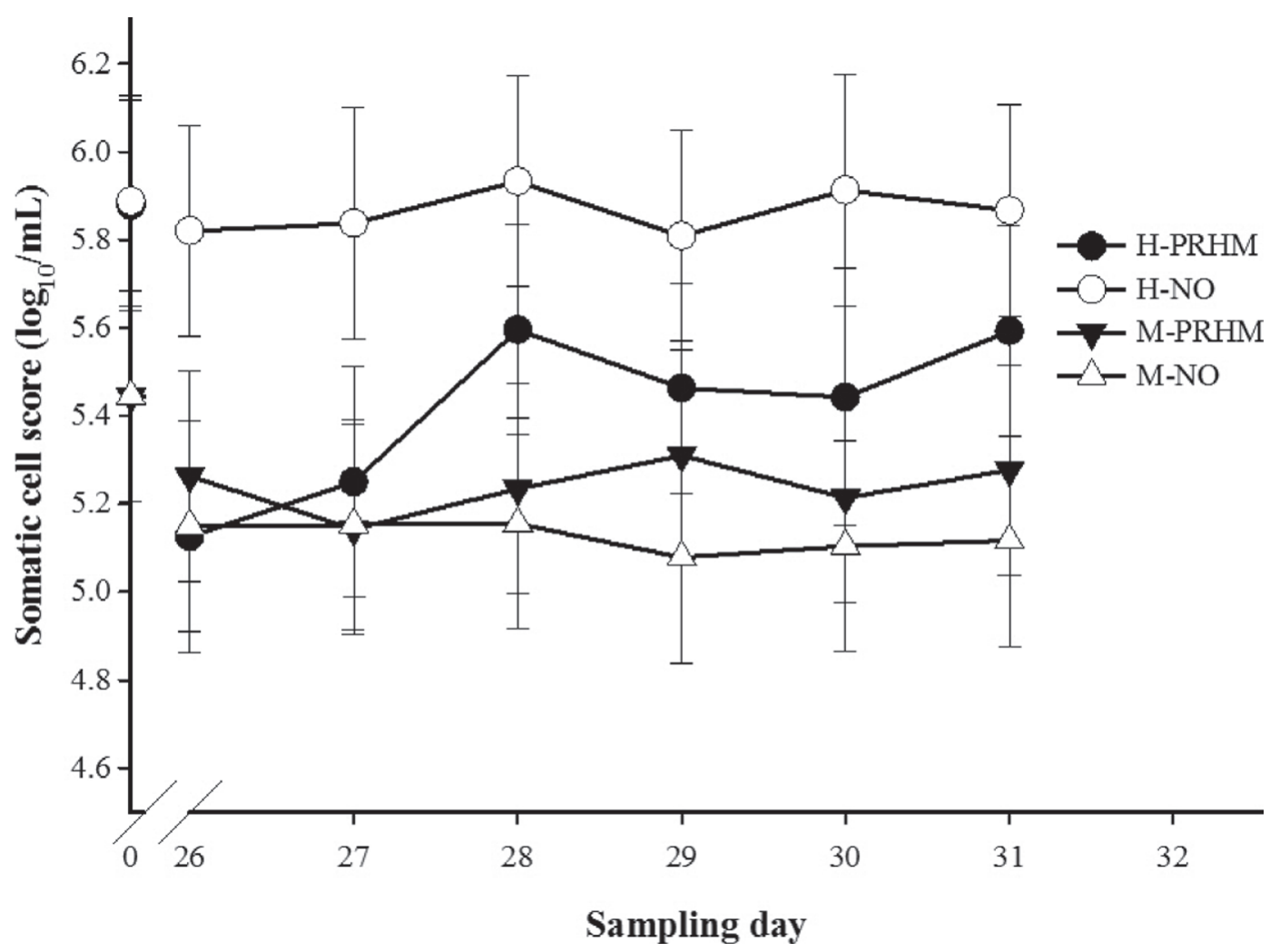

Figure 1. Daily milk SCS $\left(\log _{10}\right.$ cells $\left./ \mathrm{mL}\right)$ of dairy cows with initial moderate $(\mathrm{M})$ or high $(\mathrm{H})$ SCC after supplementation with a novel phytobiotics-rich herbal mixture (PRHM) or not (NO). The $P$-values for PRHM, initial SCC in milk, and 2-way interaction of PRHM and initial SCC in milk were $0.12,0.20$, and $<0.01$, respectively. The pooled SEM was 0.118 .

$=0.06)$ compared with unsupplemented cows. No interaction was detected between SCC levels and PRHM supplementation for ruminal fermentation $(P>0.10$; Table 4).

\section{Plasma Metabolites}

Supplementation of PRHM increased BHBA $(P=$ $0.02)$ and cholesterol $(P=0.03)$ concentrations, and decreased plasma creatinine $(P=0.04)$ compared with unsupplemented cows, whereas other metabolites were not affected by PRHM supplementation $(P>0.10)$. Cows of the high-SCC group had greater $(P=0.04)$ plasma glucose concentration but tended $(P=0.08)$ to show lower BUN concentration compared with the moderate-SCC group. No interaction effects were detected between SCC level and PRHM supplementation on plasma metabolites, with the exception of albuminto-globulin ratio $(P=0.10$; Table 5$)$. Supplementation of PRHM to cows with high SCC tended to decrease

Table 4. Ruminal fermentation characteristics of dairy cows at 2 levels of SCC in the milk after supplementation with a novel phytobiotics-rich herbal mixture (PRHM) or not (NO)

\begin{tabular}{|c|c|c|c|c|c|c|c|c|}
\hline Variable & \multicolumn{4}{|c|}{ Initial SCC level } & SEM & \multicolumn{3}{|c|}{$P$-value } \\
\hline $\mathrm{pH}$ & 5.99 & 6.22 & 6.06 & 6.02 & 0.173 & 0.73 & 0.61 & 0.48 \\
\hline Ammonia-N (mg/dL) & 4.94 & 6.12 & 4.97 & 5.42 & 0.92 & 0.39 & 0.72 & 0.70 \\
\hline Total VFA $(\mathrm{mmol} / \mathrm{L})$ & 111.5 & 103.1 & 106.8 & 113.6 & 8.62 & 0.90 & 0.68 & 0.30 \\
\hline Butyrate (mol/100 mol) & 10.5 & 10.2 & 10.1 & 9.7 & 0.72 & 0.58 & 0.56 & 0.95 \\
\hline Acetate:propionate & 2.67 & 2.81 & 2.38 & 2.88 & 0.149 & 0.05 & 0.51 & 0.21 \\
\hline
\end{tabular}


Table 5. Blood metabolites of dairy cows at 2 levels of SCC in the milk after supplementation with a novel phytobiotics-rich herbal mixture (PRHM) or not (NO)

\begin{tabular}{|c|c|c|c|c|c|c|c|c|}
\hline Variable $^{1}$ & \multicolumn{4}{|c|}{ Initial SCC level } & SEM & \multicolumn{3}{|c|}{$P$-value } \\
\hline Glucose (mg/dL) & 60.5 & 59.6 & 51.7 & 56.9 & 2.77 & 0.44 & 0.04 & 0.27 \\
\hline Total protein $(\mathrm{g} / \mathrm{dL})$ & 9.8 & 9.5 & 9.2 & 10.0 & 0.50 & 0.61 & 0.93 & 0.30 \\
\hline Albumin $(\mathrm{g} / \mathrm{dL})$ & 4.5 & 5.0 & 4.7 & 4.9 & 0.21 & 0.15 & 0.78 & 0.30 \\
\hline Creatinine $(\mathrm{mg} / \mathrm{dL})$ & 1.10 & 1.30 & 1.09 & 1.24 & 0.076 & 0.04 & 0.66 & 0.81 \\
\hline BUN (mg/dL) & 8.9 & 11.2 & 14.5 & 12.1 & 1.77 & 0.99 & 0.08 & 0.22 \\
\hline Cholesterol (mg/dL) & 309 & 234 & 310 & 294 & 19.8 & 0.03 & 0.16 & 0.18 \\
\hline Triglyceride (mg/dL) & 28.4 & 28.5 & 41.4 & 30.5 & 7.26 & 0.47 & 0.32 & 0.46 \\
\hline $\mathrm{BHBA}(\mu \mathrm{mol} / \mathrm{L})$ & 792.7 & 503.6 & 637.7 & 506.3 & 88.2 & 0.02 & 0.39 & 0.36 \\
\hline $\operatorname{AST}(\mathrm{U} / \mathrm{L})$ & 112.4 & 114.6 & 139.8 & 109.0 & 12.14 & 0.25 & 0.38 & 0.18 \\
\hline $\operatorname{ALP}(\mathrm{U} / \mathrm{L})$ & 102.1 & 74.0 & 83.8 & 73.2 & 14.41 & 0.21 & 0.53 & 0.57 \\
\hline
\end{tabular}

${ }^{1} \mathrm{AST}=$ aspartate aminotransferase; ALT $=$ alanine aminotransferase; ALP $=$ alkaline phosphatase.

the albumin-to-globulin ratio compared with unsupplemented cows $(P=0.07)$, but did not affect cows with moderate SCC.

\section{DISCUSSION}

The public awareness of potential health risks brought about by excessive use of in-feed antibiotics and synthetic pharmaceuticals has recently increased. This has encouraged the use of various forms of phytobiotics in animal nutrition. In ruminant nutrition, phytobiotics are largely used as rumen fermentation modulators (Khiaosa-ard and Zebeli, 2013), and also as antioxidant and antiinflammatory supplements (Jungbauer and Medjakovic, 2012). The antioxidant activity of herbs and spices, especially those used in the present study, often originates from their phenolic compounds. Herbal plants used in the present study provided a large amount of phenolic compounds, which contributed to potent antioxidant activity (the correlation of total phenolics and DPPH-RSA was 0.90). For example, carnosic acid as the major phenolic constituent of rosemary leaves exhibits potent antioxidant activity often stronger than some synthetic antioxidants (Charles, 2013). Additionally, the main bioactive compounds of cinnamon bark (cinnamaldehyde; Gowder et al., 2006), clove bud (eugenol and gallic acid; Kramer et al., 1985), and turmeric (curcumin and other curcuminoids; Aftab and Vieira, 2010) as well as their raw extracts are known to exhibit strong lipophilic and hydrophilic antioxidant properties (Wu et al., 2004). Also, synergism among herbal combinations has been observed (Aftab and Vieira, 2010). Therefore, focusing on identifying synergistic interactions provides a possible way to minimize oxidative stress, lower consumption dose, and save on costs.
Recent experiments have shown that these phytobiotics might be more effective in animals when they are under physiological or environmental stress conditions, or both (Gobert et al., 2009; Yang et al., 2010). The current study sought to evaluate the effectiveness of PRHM supplementation to modulate performance, udder health, and metabolic status in cows with moderate and high levels of SCC in the milk. Elevated levels of milk SCC reflect impaired udder health, representing an important stressful situation, which is associated with lowered performance and impaired metabolic health status of the cows (Schukken et al., 2003).

\section{Feed Intake and Performance}

Cows with higher initial SCC levels had lower milk yields. Overall consent exists in the literature that mammary infections, either experimentally induced or not, have the potential to drastically lower milk yield (Scaletti et al., 2003; Schukken et al., 2003; Weiss et al., 2004). Several factors, including lowered DMI, increased demands in energy and nutrients of the immune system in response to inflammation (Zebeli and Metzler-Zebeli, 2012), and damage of secretory tissue and its replacement with fibrous tissue, lead to a temporal or permanent decrease in milk yield during mammary infections (Zhao and Lacasse, 2008).

Many studies have provided evidence that bioactive compounds found in the PRHM in the present study elicit antiinflammatory activity. For example, curcumin, a principal component of turmeric, a polyphenolic compound present in cinnamon bark, and rosmarinic acid, a principal phenolic acid in rosemary leaves, show strong antiinflammatory activities (Jungbauer and Medjakovic, 2012). Also, a recent study (Fu et al., 
2014) demonstrated that curcumin exerted antiinflammatory effects in a lipopolysaccharide-induced mouse mastitis model, which may be related to inhibition of proinflammatory cytokine production by suppressing cellular nuclear factor $\kappa \mathrm{B}$ activation of the immune cells. Those researchers suggested curcumin as a potential therapeutic agent against mastitis. Because milk SCC is considered an important indicator of mammary health, the lowered levels of SCC in cows supplemented with PRHM suggest an ameliorated udder health status in the latter cows. Although the exact mechanism(s) behind positive effects of PRHM supplementation on SCC level in the milk are not yet clear, it is possible that administration of PRHM might have alleviated the stressful conditions in cows brought about by poor mammary health status. Because the antioxidant potential of an organism may be impaired during mammary infections, it is feasible to suggest that providing a large amount of hydrophilic and lipophilic phenols with potent antioxidant or co-antioxidant activity might be a beneficial strategy to protect mammary cells against the adverse effects of free radicals. In agreement with our experiment, supplementation of rosemary extract at $1.2 \mathrm{~g} / \mathrm{d}$ or a mixture of essential oils to lactating ewes (Giannenas et al., 2011; Chiofalo et al., 2012) and concentrated pomegranate extract at a rate of $4 \%$ of diet DM to dairy cows (Shabtay et al., 2012) resulted in lowered SCC in the milk compared with respective control groups.

Another interesting finding of the current study was that PRHM supplementation enhanced DMI and performance of the cows. Interestingly, these effects were different in cows with initial moderate versus high SCC in the milk, indicating specific potentials for PRHM supplementation to enhance the performance in cows with high SCC in the milk. A recent study by Shabtay et al. (2012) reported that addition of pomegranate extract to dairy cow diets resulted in higher milk production. The same authors also found that the effects of pomegranate addition on milk yield were stronger in cows suffering from chronic mastitis in mid lactation and in cows in early lactation than in healthy midlactation cows (Shabtay et al., 2012). The study by Yang et al. (2010) also showed that supplementation of a low dose of cinnamaldehyde, the main component of cinnamon oil, to finishing feedlot diets alleviated the decrease in feed intake that occurred at the start of the experimental period when animals were exposed to various stresses, such as reallocation or ruminal acidosis (Yang et al., 2010). It is known that steers go through an inflammatory state during their transition from the backgrounding to the finishing period (Ametaj et al., 2009), whereas the antiinflammatory activities of cinnamaldehyde (Kim et al., 2010) might have helped in mitigating adverse effects of inflammatory responses in the study by Yang et al. (2010). Other studies also have shown that supplementation of herbal extracts to heat-stressed cows increased nutrient intake and mitigated the negative effects of heat stress on performance (Boyd et al., 2012; Pan et al., 2014). Collectively, these results support the hypothesis that PRHM supplementation is more effective in animals under chronic stress conditions.

\section{Ruminal Fermentation}

Results of this experiment also indicated that PRHM supplementation shifted ruminal fermentation toward propionate formation and against acetate, without affecting the total VFA concentration. Our findings are consistent with the results obtained by Tekippe et al. (2013), who supplemented an essential oil product based on eugenol and cinnamaldehyde to dairy cows. In fact, the propionate-enhancing properties of phytobiotic feed additives in the rumen are well known in cattle fed grain-rich diets (Khiaosa-ard and Zebeli, 2013) as in the current study. The strategy of supporting propionate formation is particularly effective in cows in early lactation, which are under a strong negative energy balance, and also in beef cattle. An increase in propionate formation in the rumen, which is converted to glucose via hepatic gluconeogenesis and serves as the main energy source in the udder for milk synthesis (Aschenbach et al., 2010), may explain the increase in milk yield of cows supplemented with PRHM in our study. A greater DMI of the supplemented cows potentially contributed to greater milk yield as well.

However, the enhancement of propioniogenesis in the rumen in response to PRHM feeding happened at the expense of acetate, which tended to decrease in the rumen of cows supplemented with PRHM. The decrease in milk fat content in cows supplemented with PRHM can, therefore, be partly attributed to this lower formation of acetate in the rumen, which may have led to lower substrate availability for de novo FA synthesis in the udder. The decrease in milk fat content can also be attributed to a dilution effect in response to the production of larger amounts of milk in PRHM-supplemented cows. However, regardless of the type of dietary treatment consumed, milk fat depression occurred on all diets. The most plausible explanation for this is the feeding of low-forage/highconcentrate proportion to cows in our study $(\sim 32 \%$ forage of diet DM) to support high energy demands for milk production of the cows. Due to the low quality of the forages in Iran, large amounts of concentrate are typically fed to high-producing dairy cows to meet their energy requirements. In our experiment, the low-forage 
diet eventually led to low milk fat content because of lowered daily mean ruminal $\mathrm{pH}$, acetate-to-propionate ratio, and butyrate proportion in the rumen fluid; all these factors are known to induce milk fat depression in cows (Zebeli et al., 2010). Also, the high ambient temperature during the experiment may partially explain this fact. This study was conducted from May through July and the average of the temperature-humidity index (THI) value for this period was 67.8. Ahangaran (2013) evaluated the effects of THI on milk yield and milk composition of dairy cows in climatic conditions of 7 industrial dairy cattle farms in Isfahan Province in Iran. They suggested that the threshold of THI to trigger heat stress in these farms was 65 , which was associated with lower feed intake, milk production, and milk fat content.

\section{Plasma Metabolites}

Associations among plasma metabolites, immunological and oxidative stress variables, and udder health have been described in multiple studies (Nyman et al., 2008; Jóźwik et al., 2012). Inflammatory conditions increase oxidative stress products, whereby the depletion of antioxidant reserves in response to inflammation sates, such as during subclinical mastitis, can further exacerbate metabolic health status of the cows (Waldron et al., 2006). Inflammation is known to cause an initial state of hyperglycemia due to enhanced glycogenolysis and gluconeogenesis in response to rapid activation of the immune cells (Waldron et al., 2006). Similar to our results, Waldron et al. (2006) observed elevated plasma insulin and glucose concentrations after experimentally induced mastitis. The increase in glucose concentration in the plasma of high-SCC cows in our study can also be explained by lower milk yield, and, hence, lower glucose utilization for milk synthesis in these cows. The high-SCC cows tended to consume less feed but they produced roughly 3 to $4 \mathrm{~kg}$ less milk than their counterparts of the moderate-SCC group.

Despite being in mid lactation and having relatively high DMI, cows in this study still were in mild negative energy balance. The higher energy intake in response to PRHM supplementation could not completely meet the energy and protein requirements for incremented milk production. These cows had greater BFT loss during the experimental period and also elevated BHBA concentrations in the plasma, indicating enhanced ketogenesis and greater body fat mobilization. However, the BHBA concentrations in our study were within the physiological ranges and did not indicate a subclinical ketotic state (Tedesco et al., 2004). Also, plasma creatinine concentration was lower in cows supplemented with PRHM, suggesting more intensive mobilization of skeletal muscle protein in the latter cows (Bruckmaier et al., 1998). Our results indicate an apparent energetic shift away from gaining body reserves to milk output in response to PRHM supplementation in cows.

Interestingly, the results of the present experiment suggest improved hepatic nutrient metabolism in cows supplemented with PRHM, which is evidenced by higher plasma cholesterol concentration. It is known that blood cholesterol in ruminants derives mainly from endogenous synthesis mostly in the hepatic tissue, whereby acetate and glucose serve as the major precursors to the de novo synthesis of cholesterol in ruminants (Liepa et al., 1978). Because plasma glucose and rumen acetate concentrations were lower in the PRHM group, which indicate lower cholesterol synthesis, we speculate that other mechanism(s) related to the clearance of cholesterol from the circulation might have been involved in the changes in plasma cholesterol concentration in our study. Because the clearance of plasma cholesterol is enhanced during inflammatory states (Zebeli et al., 2011), greater cholesterol concentration in cows fed PRHM could, therefore, be attributed to the antiinflammatory role of PRHM, which might have led to a lower clearance of cholesterol. Likewise, Hosoda et al. (2006) reported that feeding clove bud at $5 \%$ of DM resulted in a higher cholesterol concentration compared with the control diet.

Many investigations in nonruminants have reported that phytobiotics supplementation, such as those used in the present study, can be used to alleviate or treat hepatic disorders without any side effects (Amin and Hamza, 2005; Moselhy and Ali, 2009; Singh et al., 2011). To our knowledge, limited information exists regarding the hepatoprotective activity of PRHM and their bioactive components in ruminants, including dairy cows. Tedesco et al. (2004) reported that feeding silymarin, a standardized extract from Silybum marianum seed, had no hepatoprotective effects in dairy cows during the transition period. They proposed that the effect of silymarin on plasma metabolites may be observable only in a hyperlipidemic conditions. Our cows were not in a hyperlipidemic condition, which probably explains why no effects of PRHM were observed on the liver enzymes in our study.

\section{CONCLUSIONS}

Data from the present study showed that high SCC in milk are associated with lowered performance; however, the supplementation of PRHM was effective in lowering the SCC and enhancing performance in mid-lactation cows having moderate or high SCC, suggesting an ameliorated mammary health status. This supplementation also exerted positive effects on feed 
intake of the cows and propionate formation in the rumen, resulting in improved milk production. Overall, the study suggests PRHM supplementation as an effective strategy to enhance performance and lower SCC; in particular, in cases when cows have high SCC in the milk. Further investigations are warranted to elucidate the mechanism(s) behind positive effects of PRHM supplementation on udder health and performance of the cows. Also, because PRHM supplementation lowered the BFT of the supplemented cows, further research should evaluate the long-term effects of PRHM supplementation, particularly in terms of metabolic health status and reproduction performance of the cows.

\section{ACKNOWLEDGMENTS}

The authors thank FKA Co. for funding this research. The authors express their appreciation to J. Jalilnejad, general manager of FKA Co., and the farm veterinarians including M. Safahani-Langroodi, M. Khosravi, and M. Sahabi and staff at FKA Co., including A. Khamesi-Tehrani, H. Beiranvand, A. R. Shafie, S. Omidian, A. R. Mirzakhani, and M. Mohammadi for their kind assistance and diligent animal care; and to A. Bakhtari, S. Kargar, H. Ahangaran, B. BaghbanzadehNobari, H. Omidi, A. M. Vatankhah, and H. Khoshouei (IUT, Isfahan, Iran) for their help in conducting this experiment.

\section{REFERENCES}

Aftab, N., and A. Vieira. 2010. Antioxidant activities of curcumin and combinations of this curcuminoid with other phytochemicals. Phytother. Res. 24:500-502.

Ahangaran, H. 2013. Study the temperature-humidity index and its effect on performance of dairy cows in Isfahan. MSc Thesis. Isfahan University of Technology, Isfahan, Iran.

Ametaj, B. N., K. M. Koenig, S. M. Dunn, W. Z. Yang, Q. Zebeli, and K. A. Beauchemin. 2009. Backgrounding and finishing diets are associated with inflammatory responses in feedlot steers. J. Anim. Sci. 87:1314-1320.

Amin, A., and A. A. Hamza. 2005. Hepatoprotective effects of Hibiscus, Rosmarinus and Salvia on azathioprine-induced toxicity in rats. Life Sci. 77:266-278.

AOAC. 1990. Official Methods of Analysis. Volume 2. 15th ed. Association of Official Analytical Chemists, Arlington, VA.

Asai, A., K. Nakagawa, and T. Miyazawa. 1999. Antioxidative effects of turmeric, rosemary and capsicum extracts on membrane phospholipid peroxidation and liver lipid metabolism in mice. Biosci. Biotechnol. Biochem. 63:2118-2122.

Aschenbach, J. R., N. B. Kristensen, S. S. Donkin, H. M. Hammon, and G. B. Penner. 2010. Gluconeogenesis in dairy cows: The secret of making sweet milk from sour dough. IUBMB Life 62:869-877.

Bakırel, T., U. Bakırel, O. Ü. Keleş, S. G. Ülgen, and H. Yardibi. 2008. In vivo assessment of antidiabetic and antioxidant activities of rosemary (Rosmarinus officinalis) in alloxan-diabetic rabbits. J. Ethnopharmacol. 116:64-73.

Bamdad, F., M. Kadivar, and J. Keramat. 2006. Evaluation of phenolic content and antioxidant activity of Iranian caraway in comparison with clove and BHT using model systems and vegetable oil. Int. J. Food Sci. Technol. 41(Suppl. s1):20-27.
Bouwstra, R. J., M. Nielen, J. R. Newbold, E. H. J. M. Jansen, H. F. Jelinek, and T. van Werven. 2010. Vitamin E supplementation during the dry period in dairy cattle. Part II: Oxidative stress following vitamin E supplementation may increase clinical mastitis incidence postpartum. J. Dairy Sci. 93:5696-5706.

Boyd, J., J. W. West, J. K. Bernard, and S. S. Block. 2012. Effects of plant extracts on milk yield and apparent efficiency of lactating dairy cows during hot weather. Prof. Anim. Sci. 28:338-343.

Broderick, G. A., and J. H. Kang. 1980. Automated simultaneous determination of ammonia and total amino-acids in ruminal fluid and in vitro media. J. Dairy Sci. 63:64-75.

Bruckmaier, R. M., L. Gregoretti, F. Jans, D. Faissler, and J. W. Blum. 1998. Longissimus dorsi muscle diameter, backfat thickness, body condition scores and skinfold values related to metabolic and endocrine traits in lactating dairy cows fed crystalline fat or free fatty acids. Zentralbl. Veterinärmed. A 45:397-410.

Charles, D. J. 2013. Antioxidant Properties of Spices, Herbs and Other Sources. Springer, New York, NY.

Chiofalo, V., L. Liotta, R. Fiumanò, E. B. Riolo, and B. Chiofalo. 2012. Influence of dietary supplementation of Rosmarinus officinalis L. on performances of dairy ewes organically managed. Small Rumin. Res. 104:122-128.

Dragland, S., H. Senoo, K. Wake, K. Holte, and R. Blomhoff. 2003. Several culinary and medicinal herbs are important sources of dietary antioxidants. J. Nutr. 133:1286-1290.

Ferguson, J. D., D. T. Galligan, and N. Thomsen. 1994. Principal descriptors of body condition score in Holstein cows. J. Dairy Sci. 77:2695-2703.

Fu, Y., R. Gao, Y. Cao, M. Guo, Z. Wei, E. Zhou, Y. Li, M. Yao, Z. Yang, and N. Zhang. 2014. Curcumin attenuates inflammatory responses by suppressing TLR4-mediated NF- $\mathrm{BB}$ signaling pathway in lipopolysaccharide-induced mastitis in mice. Int. Immunopharmacol. 20:54-58.

Giannenas, I., J. Skoufos, C. Giannakopoulos, M. Wiemann, O. Gortzi, S. Lalas, and I. Kyriazakis. 2011. Effects of essential oils on milk production, milk composition, and rumen microbiota in Chios dairy ewes. J. Dairy Sci. 94:5569-5577.

Gladine, C., E. Rock, C. Morand, D. Bauchart, and D. Durand. 2007. Bioavailability and antioxidant capacity of plant extracts rich in polyphenols, given as a single acute dose, in sheep made highly susceptible to lipoperoxidation. Br. J. Nutr. 98:691-701.

Gobert, M., B. Martin, A. Ferlay, Y. Chilliard, B. Graulet, P. Pradel, D. Bauchart, and D. Durand. 2009. Plant polyphenols associated with vitamin E can reduce plasma lipoperoxidation in dairy cows given n-3 polyunsaturated fatty acids. J. Dairy Sci. 92:6095-6104.

Gowder, S. J. T., and H. Devaraj. 2006. Effect of the food flavour cinnamaldehyde on the antioxidant status of rat kidney. Basic Clin. Pharmacol. Toxicol. 99:379-382.

Hosoda, K., K. Kuramoto, B. Eruden, T. Nishida, and S. Shioya. 2006. The effects of three herbs as feed supplements on blood metabolites, hormones, antioxidant activity, IgG concentration, and ruminal fermentation in Holstein steers. Asian-australas. J. Anim. Sci. 19:35-41.

Iranian Council of Animal Care. 1995. Guide to the Care and Use of Experimental Animals, 1. Isfahan University of Technology, Isfahan, Iran.

Jóźwik, A., J. Krzyżewski, N. Strzałkowska, E. Poławska, E. Bagnicka, A. Wierzbicka, K. Niemczuk, P. Lipińska, and J. O. Horbańczuk. 2012. Relations between the oxidative status, mastitis, milk quality and disorders of reproductive functions in dairy cows- A review. Anim. Sci. Pap. Rep. 30:297-307.

Jungbauer, A., and S. Medjakovic. 2012. Anti-inflammatory properties of culinary herbs and spices that ameliorate the effects of metabolic syndrome. Maturitas 71:227-239.

Kargar, S., G. R. Ghorbani, M. Alikhani, M. Khorvash, L. Rashidi, and D. J. Schingoethe. 2012. Lactational performance and milk fatty acid profile of Holstein cows in response to dietary fat supplements and forage:concentrate ratio. Livest. Sci. 150:274-283.

Khiaosa-ard, R., and Q. Zebeli. 2013. Meta-analysis of the effects of essential oils and their bioactive compounds on rumen fermenta- 
tion characteristics and feed efficiency in ruminants. J. Anim. Sci. 91:1819-1830.

Kim, B. H., Y. G. Lee, J. Lee, J. Y. Lee, and J. Y. Cho. 2010. Regulatory effect of cinnamaldehyde on monocyte/macrophage-mediated inflammatory responses. Mediat. Inflamm. 2010:529359.

Kramer, R. E. 1985. Antioxidants in clove. J. Am. Oil Chem. Soc. $62: 111-113$.

Liepa, G. U., D. C. Beitz, and J. R. Linder. 1978. Cholesterol synthesis in ruminating and nonruminating goats. J. Nutr. 108:535-543.

Liu, R. H. 2004. Potential synergy of phytochemicals in cancer prevention: Mechanism of action. J. Nutr. 134:3479S-3485S.

Moselhy, S. S., and H. K. H. Ali. 2009. Hepatoprotective effect of cinnamon extracts against carbon tetrachloride induced oxidative stress and liver injury in rats. Biol. Res. 42:93-98.

Nyman, A. K., U. Emanuelson, K. Holtenius, K. L. Ingvartsen, T. Larsen, and K. Persson Waller. 2008. Metabolites and immune variables associated with somatic cell counts of primiparous dairy cows. J. Dairy Sci. 91:2996-3009.

Pan, L., D. P. Bu, J. Q. Wang, J. B. Cheng, X. Z. Sun, L. Y. Zhou, J. J. Qin, X. K. Zhang, and Y. M. Yuan. 2014. Effects of Radix bupleuri extract supplementation on lactation performance and rumen fermentation in heat-stressed lactating Holstein cows. Anim. Feed Sci. Technol. 187:1-8.

Politis, I. 2012. Reevaluation of vitamin E supplementation of dairy cows: bioavailability, animal health and milk quality. Animal 6:1427-1434

Rochfort, S., A. J. Parker, and F. R. Dunshea. 2008. Plant bioactives for ruminant health and productivity. Phytochemistry 69:299322.

Roussel, A.-M., I. Hininger, R. Benaraba, T. N. Ziegenfuss, and R. A. Anderson. 2009. Antioxidant effects of a cinnamon extract in people with impaired fasting glucose that are overweight or obese. J. Am. Coll. Nutr. 28:16-21.

Scaletti, R. W., D. S. Trammell, B. A. Smith, and R. J. Harmon. 2003. Role of dietary copper in enhancing resistance to Escherichia coli mastitis. J. Dairy Sci. 86:1240-1249.

Schröder, U. J., and R. Staufenbiel. 2006. Invited review: Methods to determine body fat reserves in the dairy cow with special regard to ultrasonographic measurement of backfat thickness. J. Dairy Sci. 89:1-14

Schukken, Y. H., D. J. Wilson, F. Welcome, L. Garrison-Tikofsky, and R. N. Gonzalez. 2003. Monitoring udder health and milk quality using somatic cell counts. Vet. Res. 34:579-596.

Shabtay, A., M. Nikbachat, A. Zenou, E. Yosef, O. Arkin, O. Sneer, A. Shwimmer, A. Yaari, E. Budman, G. Agmon, and J. Miron. 2012. Effects of adding a concentrated pomegranate extract to the ration of lactating cows on performance and udder health parameters. Anim. Feed Sci. Technol. 175:24-32.

Shukri, R., S. Mohamed, and N. M. Mustapha. 2010. Cloves protect the heart, liver and lens of diabetic rats. Food Chem. 122:11161121.
Singh, H., P. Bedi, and B. Singh. 2011. Hepatoprotective activity of turmeric and garlic against 7-12, dimethylbenzanthracene induced liver damage in Wistar albino rats. Eur. J. Med. Plants 1:162170 .

Tedesco, D., C. Domeneghini, D. Sciannimanico, M. Tameni, S. Steidler, and S. Galletti. 2004. Silymarin, a possible hepatoprotector in dairy cows: Biochemical and histological observations. J. Vet. Med. A Physiol. Pathol. Clin. Med. 51:85-89.

Tekippe, J. A., R. Tacoma, A. N. Hristov, C. Lee, J. Oh, K. S. Heyler, T. W. Cassidy, G. A. Varga, and D. Bravo. 2013. Effect of essential oils on ruminal fermentation and lactation performance of dairy cows. J. Dairy Sci. 96:7892-7903.

Van Keulen, J., and B. A. Young. 1977. Evaluation of acid-insoluble ash as a natural marker in ruminant digestibility studies. J. Anim. Sci. 44:282-287.

Van Soest, P. J., J. B. Robertson, and B. A. Lewis. 1991. Methods for dietary fiber, neutral detergent fiber, and nonstarch polysaccharides in relation to animal nutrition. J. Dairy Sci. 74:3583-3597.

Waldron, M. R., A. E. Kulick, A. W. Bell, and T. R. Overton. 2006. Acute experimental mastitis is not causal toward the development of energy-related metabolic disorders in early postpartum dairy cows. J. Dairy Sci. 89:596-610.

Weiss, W. P., J. S. Hogan, and K. L. Smith. 2004. Changes in vitamin $\mathrm{C}$ concentrations in plasma and milk from dairy cows after an intramammary infusion of Escherichia coli. J. Dairy Sci. 87:32-37.

Wu, X., G. R. Beecher, J. M. Holden, D. B. Haytowitz, S. E. Gebhardt, and R. L. Prior. 2004. Lipophilic and hydrophilic antioxidant capacities of common foods in the United States. J. Agric. Food Chem. 52:4026-4037.

Yang, W. Z., B. N. Ametaj, C. Benchaar, M. L. He, and K. A. Beauchemin. 2010. Cinnamaldehyde in feedlot cattle diets: Intake, growth performance, carcass characteristics, and blood metabolites. J. Anim. Sci. 88:1082-1092.

Zebeli, Q., D. Mansmann, H. Steingass, and B. N. Ametaj. 2010. Balancing diets for physically effective fibre and ruminally degradable starch: A key to lower the risk of sub-acute rumen acidosis and improve productivity of dairy cattle. Livest. Sci. 127:1-10.

Zebeli, Q., and B. U. Metzler-Zebeli. 2012. Interplay between rumen digestive disorders and diet-induced inflammation in dairy cattle. Res. Vet. Sci. 93:1099-1108.

Zebeli, Q., S. Sivaraman, S. M. Dunn, and B. N. Ametaj. 2011. Intermittent parenteral administration of endotoxin triggers metabolic and immunological alterations typically associated with displaced abomasum and retained placenta in periparturient dairy cows. J. Dairy Sci. 94:4968-4983.

Zhao, X., and P. Lacasse. 2008. Mammary tissue damage during bovine mastitis: Causes and control. J. Anim. Sci. 86(Suppl. 1):57-65. 